
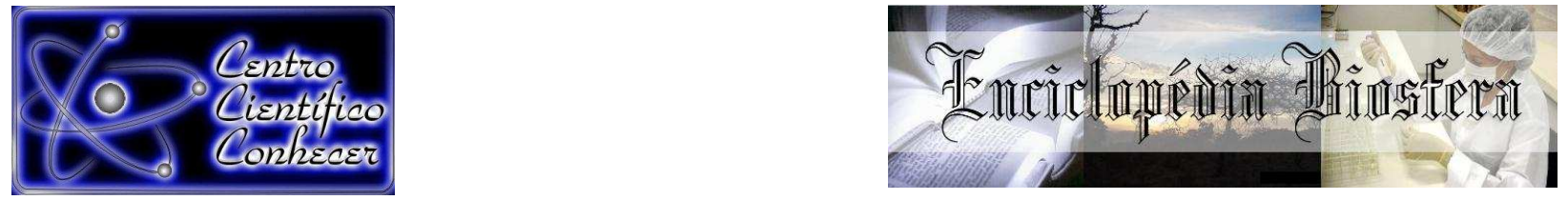

\title{
EFEITO DO BORO E POTÁSSIO NA FORMAÇÃO DO AÇAIZEIRO EM LATOSSOLO AMARELO DO NORDESTE PARAENSE
}

\author{
Carlos Alberto Costa Veloso ${ }^{1}$, Arystides Resende Silva $^{2}$, Agust Sales $^{3}$ \\ ${ }^{1}$ Pesquisador Embrapa Amazônia Oriental, Laboratório de Solos, Belém, Brasil - Pará \\ (carlos.veloso@embrapa.br) \\ ${ }^{2}$ Pesquisador Embrapa Amazônia Oriental, Laboratório de Solos, Belém, Brasil - Pará \\ ${ }^{3}$ Graduando em Engenharia Florestal da Universidade do Estado do Pará, Paragominas - \\ Brasil
}

Recebido em: 08/09/2015 - Aprovado em: 14/11/2015 - Publicado em: 01/12/2015 DOI: http://dx.doi.org/10.18677/Enciclopedia_Biosfera_2015_142

\begin{abstract}
RESUMO
A cultura do açaizeiro possui grande importância no contexto agrícola paraense, entretanto, dispõe-se de poucos resultados de pesquisa que proporcionem sustentação ao cultivo racional. O objetivo deste trabalho foi determinar os níveis de potássio e boro adequados para a fase de formação e produção do açaizeiro em áreas de terra firme. O trabalho foi realizado em área de produtor no município de Inhangapi, Pará. O delineamento experimental utilizado foi o de blocos ao acaso, em esquema fatorial $4 \times 4$, com três repetições. Os tratamentos constituíram-se por um cultivo de açaí (Euterpe oleracea Mart.) sob aplicação de quatro doses de boro (B) e quatro doses de potássio $\left(\mathrm{K}_{2} \mathrm{O}\right)$ no primeiro e segundo ano de plantio. Foram avaliadas a altura de planta e a circunferência do coleto. A dose de 20 g.planta ${ }^{-1}$ de boro aplicada em cada ano foi a mais indicada, aliada ao fornecimento de 128 e 202 g.planta ${ }^{-1}$ de potássio no primeiro ano e segundo ano, respectivamente. Os dois primeiros anos indicaram que o boro é importante para o açaizeiro, assim como o equilíbrio com o potássio. Entretanto, a frequência e quantidade de aplicação de boro deve ser estudada respeitando as peculiaridades locais, pois elevadas aplicações anuais desse elemento podem contribuir para ocorrência de toxidez nas plantas de açaizeiro.
\end{abstract}

PALAVRAS-CHAVE: Adubação, Euterpe oleracea Mart., micronutriente.

\section{EFFECT BORON AND POTASSIUM IN THE FORMATION OF THE AÇAÍZEIRO IN OXISOL YELLOW OF THE NORTHEAST PARAENSE}

\begin{abstract}
The culture of the açaí has large importance in Paraense agricultural context, however, dispose of few search results that provide support to the rational cultivation. The objective of this study was to determine the potassium and boron levels suitable to the stage of formation and production of açaí in of solid ground areas. The work was carried out at producer area in the municipality of Inhangapi, Pará. The experimental design was randomized blocks in a factorial $4 \times 4$, with three replications. The treatments consisted by a cultivation of acaí (Euterpe oleracea Mart.) under application of four doses of boron (B) and four doses of potassium $\left(\mathrm{K}_{2} \mathrm{O}\right)$ in the first and second year of planting. We evaluated the plant height and circumference of the girth. The dose of 20 g.planta $^{-1}$ boron applied every year was
\end{abstract} ENCICLOPÉDIA BIOSFERA, Centro Científico Conhecer - Goiânia, v.11 n.22; p.1059 
indicated, along with the supply of 128 and 202 g.planta potassium ${ }^{-1}$ in the first year and the second year, respectively. The first two years indicate that boron is important for açaizeiro, as well as the equilibrium with the potassium. However, the frequency and amount of boron application should be studied respecting local peculiarities, as it elevated that annual applications of this element may contribute to the occurrence of toxicity in açaizeiro plants.

KEYWORDS: Fertilization, Euterpe oleracea Mart., micronutrient.

\section{INTRODUÇÃO}

O açaizeiro (Euterpe oleracea Mart.) é uma espécie frutífera e produtora de palmito, nativa da Amazônia e tem como centro de origem o Estado do Pará, onde estão estabelecidas densas e diversificadas populações naturais (OLIVEIRA et al., 2007). A produção nacional de açaí atinge aproximadamente 203 mil toneladas de frutos ao ano, sendo o Estado do Pará responsável por 55\% do total (IBGE, 2013), dados que comprovam a importância dessa fruteira para o Pará.

Atualmente, a demanda e o potencial de mercado do açaí cresceram de maneira significativa, deixando de possuir uma dimensão regional para ganhar importância nacional e mais recentemente internacional (SANTANA et al., 2008; CONAB, 2014), graças a qualidade nutricional da bebida, resultante da maceração dos frutos, denominada vinho ou suco de açaí (FIEAM, 2013). O crescimento do mercado do açaizeiro está associado aos benefícios à saúde, que a ciência vem atribuindo à ingestão desse alimento que apresenta baixo nível de calorias, altas concentrações de vitaminas, fibras, sais minerais e à identificação de compostos com propriedades antioxidantes, por exemplo, carotenoides e flavonóides (KANG et al. 2011; RUFINO et al., 2011).

O aumento da área plantada com açaí na Amazônia, em função da demanda atual, promove seu cultivo racional visto que o extrativismo e o manejo de açaizais nativos não são capazes de atender a crescente demanda, pois apresentam baixa produção, baixo rendimento de frutos e de polpa, irregularidade na maturação dos frutos, além de plantas com caule solitário ou com variações no perfilhamento, baixa tolerância ao déficit hídrico, dentre outros fatores associados à baixa fertilidade e à elevada acidez dos solos (FOY, 1974). À medida que os cultivos vão se intensificando, o empobrecimento químico dos solos vai se tornando mais expressivo devido à extração dos nutrientes pelas plantas, exportação pelas colheitas e pelas perdas no solo via lixiviação, erosão e fixação reduzindo a disponibilidade desses nutrientes para as plantas (SANTANA et al., 2008).

Apesar da importância da cultura do açaizeiro no contexto agrícola paraense, dispõe-se de poucos resultados de pesquisa que proporcionem sustentação ao cultivo racional. Além disso, a maioria do cultivo do açaizeiro paraense está implantada em solos de baixa fertilidade natural e com alto teor de alumínio trocável, exigindo o emprego de corretivos e fertilizantes para uma produtividade sustentada (GONÇALVES \& MEURER, 2010).

O baixo consumo de fertilizantes e corretivos de acidez ainda é uma realidade na região amazônica (CUNHA et al., 2014), apesar desta prática representar uma forma de melhorar a fertilidade destes solos, de modo a proporcionar produtividades mais rentáveis aos agricultores. Nestas condições, para a obtenção da expressão máxima da produtividade biológica da cultura, faz-se necessário a interação de diversos fatores e, dentre estes, destaca-se a aplicação de nutrientes em quantidades adequadas e em formas que possam ser assimiladas pelas plantas (WASTOWSKI et al. 2010). 
Dentre os nutrientes necessários para o desenvolvimento da planta, o boro destaca-se por participar de vários processos que são afetados pela sua deficiência, como transporte de açúcares, lignificação, estrutura da parede celular, metabolismo de carboidratos, metabolismos de RNA, respiração, metabolismo de AIA, metabolismos fenólicos, metabolismos de ascorbato, além de ter função na síntese da parede celular e integridade física da membrana plasmática (REIS et al., 2008), possuindo efeito direto no crescimento e na produtividade das plantas (MARSCHNER, 2012).

Desse modo, o objetivo deste trabalho foi determinar os níveis de boro, aliados às aplicações de potássio, adequados para a fase de formação e produção do açaizeiro em áreas de terra firme na região nordeste do Pará.

\section{MATERIAL E MÉTODOS}

O trabalho foi realizado em área de produtor no município de Inhangapi, Pará (120' $54^{\prime \prime} \mathrm{S}$ e $47^{\circ} 54^{\prime} 38^{\prime \prime} \mathrm{W}$ a uma altitude de 38 metros). O solo foi classificado como Latossolo Amarelo textura média (EMBRAPA, 2006), cujos resultados da análise química de solo da área experimental na profundidade de $0-20 \mathrm{~cm}$ foram: pH(água) 4,4; P 2 mg.dm ${ }^{-3}$; $\mathrm{K} 14 \mathrm{mg} \cdot \mathrm{dm}^{-3}$; $\mathrm{Ca}+\mathrm{Mg} \mathrm{0,9} \mathrm{cmol}_{\mathrm{c}} \cdot \mathrm{dm}^{-3}$; $\mathrm{Al} \mathrm{0,8} \mathrm{cmol}_{\mathrm{c}} \cdot \mathrm{dm}^{-3}$; $\mathrm{H}+\mathrm{Al} 4,62 \mathrm{cmol}_{\mathrm{c}} \cdot \mathrm{dm}^{-3}$. Segundo a classificação de Koppen, o clima da região é do tipo Af. A precipitação apresenta média anual de $2383 \mathrm{~mm}$. A temperatura média anual varia entre $21,6{ }^{\circ} \mathrm{C}$ e $32,5{ }^{\circ} \mathrm{C}$ e a umidade relativa do ar média anual é de $85 \%$.

O delineamento experimental utilizado foi o de blocos ao acaso, no esquema fatorial $4 \times 4$, com três repetições. Os tratamentos constituíram-se por um cultivo de açaí (Euterpe oleracea Mart.) sob aplicação de quatro doses de boro (B) e quatro doses de potássio $\left(\mathrm{K}_{2} \mathrm{O}\right)$ no primeiro e segundo ano de plantio.

Para o experimento utilizou-se um plantio de 256 plantas no espaçamento $6 \times 4$ $\mathrm{m}$. No primeiro ano, foram testadas quatro doses de $\mathrm{K}_{2} \mathrm{O}$ (fornecido na forma de $\mathrm{KCl}$ ) e B (fornecido na forma de borex) nas proporções 0, 42, 84, 126 g.planta ${ }^{-1}$ e 0,10 , 20 e 30 g.planta ${ }^{-1}$, respectivamente. Foram fornecidas doses constantes de nitrogênio (200 g.planta ${ }^{-1}$ de uréia), fósforo (120 g.cova ${ }^{-1}$ de Arad) por ocasião do plantio e 30 g.planta ${ }^{-1}$ de sulfato de magnésio.

Em função dos resultados do primeiro ano foram definidas as doses para 0 segundo ano, sendo $\mathrm{K}_{2} \mathrm{O}$ aplicado nas proporções de $0,120,240$ e 360 g.planta ${ }^{-1}$ e 0, 20, 40 e 60 g.planta ${ }^{-1}$ para o B. As doses de nitrogênio foram de 150 g.planta $^{-1}$ de uréia, de fósforo 150 g.planta ${ }^{-1}$ de Arad e de magnésio 50 g.planta $^{-1}$ de sulfato de magnésio. Utilizou-se parcelas experimentais formadas por oito plantas em cada linha, sendo as seis plantas centrais consideradas úteis, onde determinou-se a altura de planta $(\mathrm{cm})$ e circunferência do coleto $(\mathrm{cm})$.

Os resultados foram avaliados estatisticamente, através de análise de variância (teste $\mathrm{F}$ ), para todas as variáveis. Curvas de regressão foram ajustadas para avaliação das respostas à aplicação de $\mathrm{K}_{2} \mathrm{O}$ e $\mathrm{B}$ em função das variáveis.

\section{RESULTADOS E DISCUSSÃO}

A interação da aplicação das doses de potássio e boro para a variável altura de planta (ADP) do açaizeiro com um e dois anos de idade estão apresentados na Figura 1. Observou-se que a aplicação de potássio na ausência de boro reduziu a ADP com um ano de idade a partir de 42 g.planta $^{-1}$ de potássio, ocorrendo inclusive deficiência de boro. A aplicação de 20 e $30 \mathrm{~g}$. planta ${ }^{-1}$ de boro reduziu a ADP a partir de 84 g.planta $^{-1}$ de potássio. A maior ADP com um ano de idade foi de 95,6 cm 
obtida com a aplicação de 10 g.planta ${ }^{-1}$ de boro aliada a 128 g.planta ${ }^{-1}$ de potássio (Figura 1). SILVA et al. (2014b), ao avaliarem os efeitos de diferentes doses de boro no crescimento do mamoeiro, verificaram que a ausência de boro reduziu drasticamente o crescimento das plantas e as aplicações de boro confirmou a influência desse elemento no desenvolvimento das plantas.

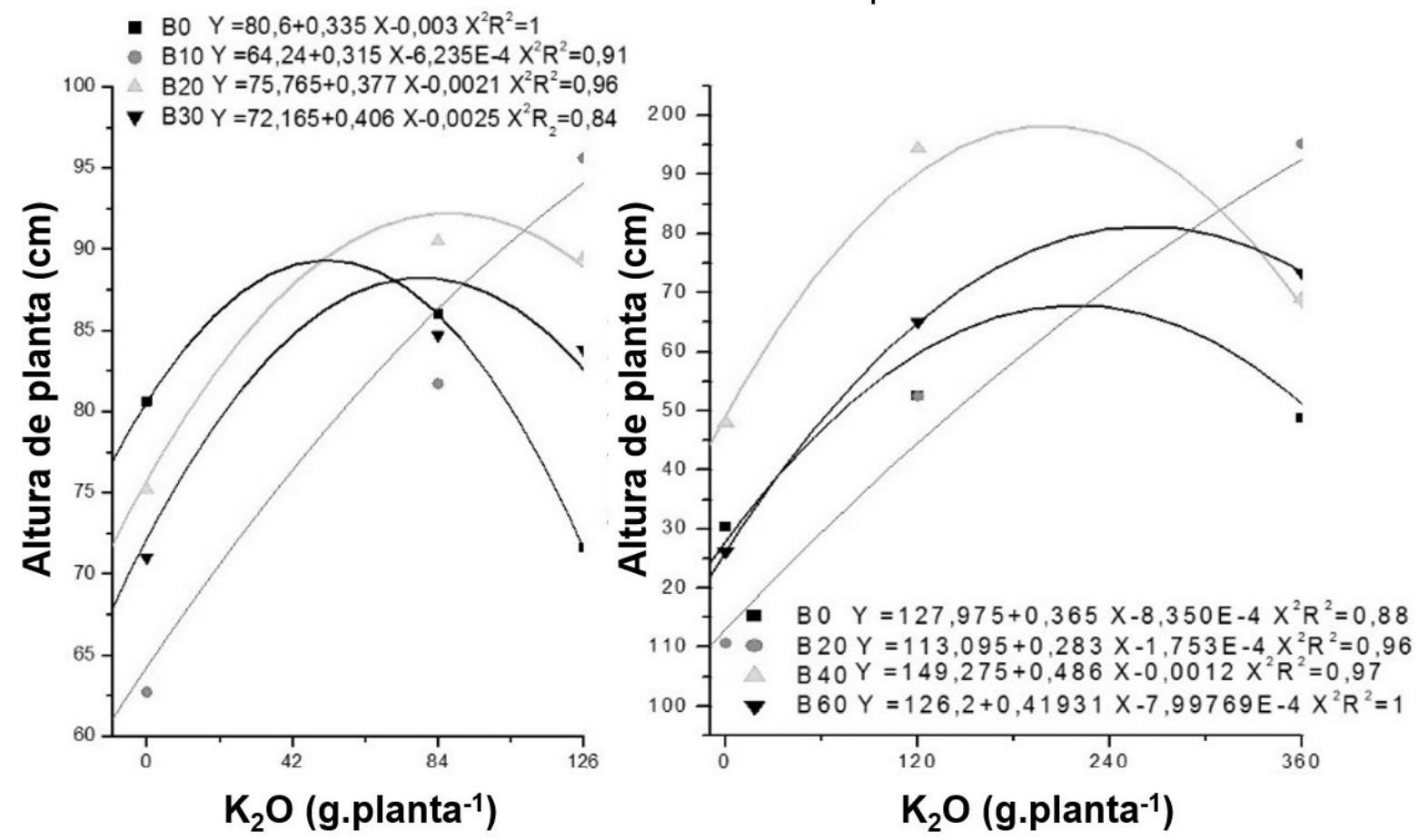

FIGURA 1. Efeito da interação das doses de potássio e de boro na altura de plantas de açaizeiro com um e dois anos de idade.

O efeito da interação das doses de potássio e boro na ADP do açaizeiro com dois anos de idade indicaram que a partir de 240 g.planta $^{-1}$ de potássio na ausência de boro e na presença de 40 e 60 g.planta ${ }^{-1}$ de boro, houve declínio de ADP (Figura 1). Isso demonstra que a deficiência e altos teores de boro geram danos ao açaizeiro, sendo necessário as aplicações de potássio e boro em equilíbrio, ajustadas às condições do solo local. ZHOU et al. (2010), em estudo onde foi avaliado o crescimento de teca (Tectona grandis) sob aplicações de $\mathrm{B}$ e $\mathrm{Ca}$, indicaram efeito significativo somente quando esses elementos atuaram em interação nas proporções adequadas.

A aplicação da dose de 60 g.planta $^{-1}$ de boro causou efeito fitotóxico nas plantas provavelmente resultado do acúmulo desse elemento nas regiões de maior atividade metabólica (MALAVOLTA, 2006). Determinados níveis de boro podem facilmente tornar-se tóxico às plantas, em compensação, elevados teores de boro podem diminuir o crescimento das raízes em razão da abundância desse elemento e a não necessidade de expansão radicular em virtude do aumento da superfície de contato para busca do mineral (MIWA \& FUJIWARA, 2010). Esses efeitos mostram que 0 açaizeiro é pouco tolerante a elevados níveis de boro, igualmente aos resultados descritos por SILVA JR. et al. (2014), no trabalho em que foi avaliado o efeito de doses de boro no crescimento de plantas jovens de mogno, onde as doses máximas ocasionaram sintomas de toxidez, como clorose e necrose de folhas velhas.

EUBA NETO et al. (2014), no estudo em que verificaram a resposta do girassol à adição de boro em ordens de solos com texturas diferentes, relataram a 
influência das doses de boro no desenvolvimento da planta e indicaram os níveis críticos e tóxicos de boro nos solos, que variaram de 0,34 a $0,55 \mathrm{mg} \cdot \mathrm{kg}^{-1}$ e de $0,8 \mathrm{a}$ $1,0 \mathrm{mg} \cdot \mathrm{kg}^{-1}$, respectivamente.

A dose máxima estimada de potássio na presença de 40 g.planta ${ }^{-1}$ de boro foi de 202,55 g.planta ${ }^{-1}$ de potássio que correspondeu à maior ADP $(198,47 \mathrm{~cm})$. A aplicação da dose de 20 g.planta $^{-1}$ de boro no segundo ano indicou aumento gradual de ADP na medida em que aumentou-se a dosagem de potássio variando a ADP de 110 a $192,78 \mathrm{~cm}$ (Figura 1), corroborando com os resultados de SILVA et al. (2014a), em estudo onde foi avaliado a adubação boratada na cultura do arroz, em que relataram aumento gradual de altura de planta à medida que aumentava a dosagem de boro.

Diferentemente dos resultados encontrados por SOUZA et al. (2010), em que não verificaram diferença significante em nenhum dos parâmetros de crescimento analisados em plantas de mogno em razão da adubação boratada e calagem. NOMURA et al. (2011), também não verificaram influência significativa na altura e diâmetro do pseudocaule, ao avaliarem o efeito da adubação de boro em plantas adultas de banana.

Com relação à variável circunferência do coleto (CDC) no primeiro ano de cultivo do açaizeiro, os resultados foram semelhantes aos obtidos à variável ADP. Notou-se declínio gradual de CDC na dosagem 30 g.planta ${ }^{-1}$ de boro e na aplicação a partir de 84 g.planta ${ }^{-1}$ de potássio aliado à ausência e à aplicação de 20 g.planta ${ }^{-1}$ de boro. A dose máxima estimada de 89 g.planta $^{-1}$ de potássio na presença de 10 g.planta $^{-1}$ de boro foi a que proporcionou a maior $\operatorname{CDC}(11,6 \mathrm{~cm})$ (Figura 2). ARAÚJO \& SILVA (2012), ao avaliarem o efeito das concentrações de boro no desenvolvimento do algodoeiro, notaram aumento linear nas variáveis altura e diâmetro caulinar à medida que aumentava as concentrações de boro, confirmando a ligação direta do nutriente ao desenvolvimento da planta controlando a produção de importantes reguladores de crescimento.
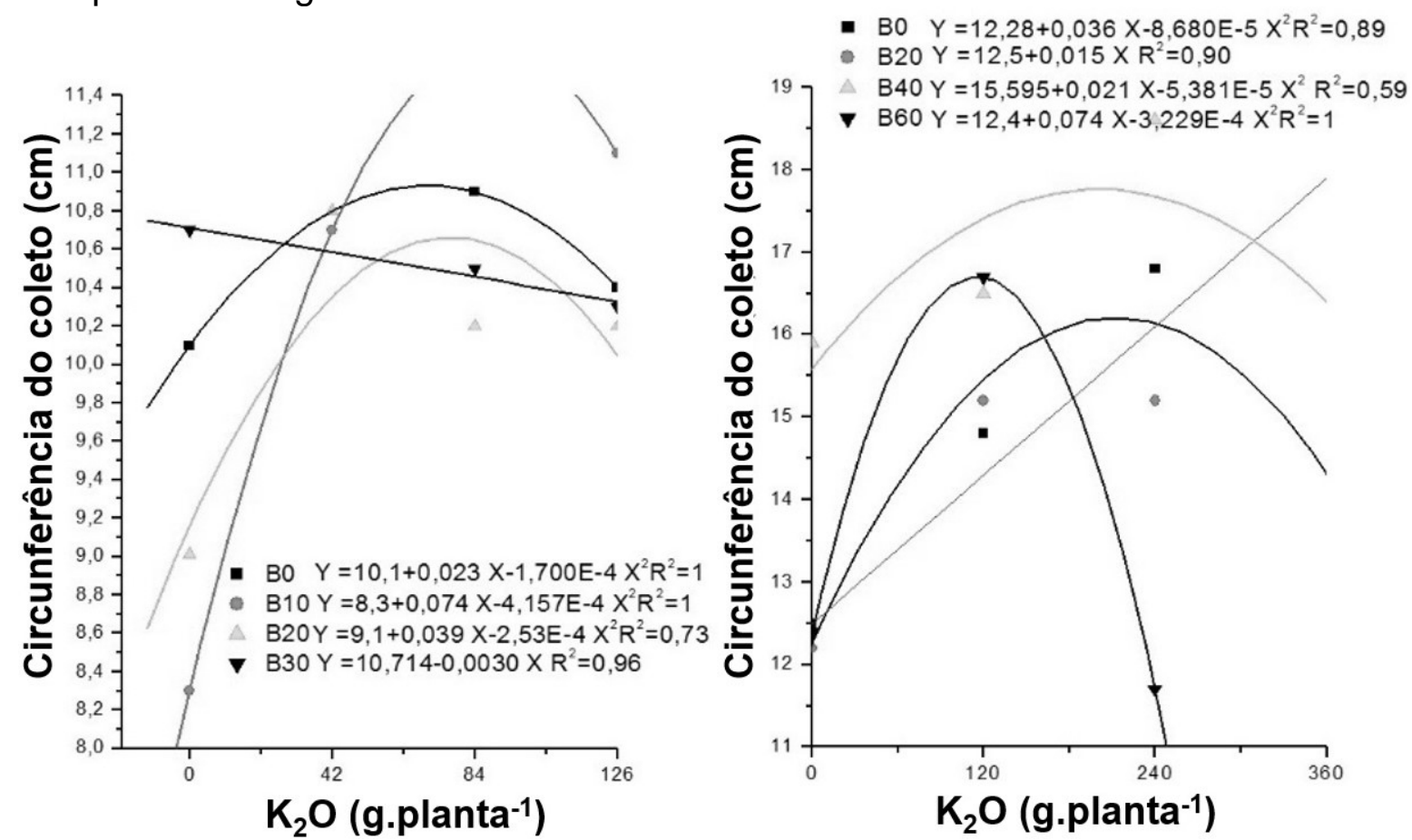

FIGURA 2. Efeito da interação das doses de potássio e de boro na circunferência do coleto de plantas de açaizeiro com um e dois anos de idade. 
A CDC do açaizeiro com dois anos de plantio reduziu a partir da aplicação de 120 g.planta $^{-1}$ de potássio na presença de 60 g.planta $^{-1}$ de boro, já as plantas com ausência e dosagem de 40 g.planta ${ }^{-1}$ de boro apresentaram redução de CDC na presença de 240 g.planta ${ }^{-1}$ de potássio. A aplicação de 40 g.planta $^{-1}$ de boro em combinação com a dose máxima estimada de 195 g.planta $^{-1}$ de potássio resultou em $17,64 \mathrm{~cm}$ de CDC. O maior valor de CDC $(18,2 \mathrm{~cm})$ foi obtido com 360 g.planta ${ }^{-1}$ de potássio na presença de 20 g.planta ${ }^{-1}$ de boro (Figura 2), indicando dosagem suficiente do micronutriente boro para atender a necessidades nutricionais do açaizeiro nos dois primeiros anos de cultivo.

Segundo COSTA et al. (2014), o uso de boro na adubação não deve ser de forma indiscriminada, visto que esse elemento se aplicado em excesso pode tornarse tóxico, razão pela qual torna-se necessário conhecer os níveis adequados deste micronutriente no solo e na planta. Os dois primeiros anos indicaram que o boro é importante para o açaizeiro, haja vista a ocorrência dos sintomas de deficiências nos tratamentos sem aplicação desse micronutriente. A dose de 20 gramas por planta de boro aplicada em cada ano foi a mais indicada, aliada ao fornecimento de 128 gramas por planta de potássio no primeiro ano e 202 gramas por planta de potássio no segundo ano.

\section{CONCLUSÃO}

Confirmou-se a importância do boro para o cultivo do açaizeiro, assim como o equilíbrio com o potássio. Entretanto, A frequência e quantidade de aplicação de boro deve ser estudada respeitando as peculiaridades locais, que elevadas aplicações anuais desse elemento podem contribuir para ocorrência de toxidez nas plantas de açaizeiro.

\section{REFERÊNCIAS}

ARAÚJO, É. O.; SILVA, M. A. C. Interação boro e zinco no crescimento, desenvolvimento e nutrição do algodoeiro. Revista Brasileira de Ciências Agrárias (agrária). v. 7, suplemento, p. 720-727. 2012. DOI:10.5039/agraria.v7isa1848.

COMPANHIA NACIONAL DE ABASTECIMENTO (Conab). 2014. Conjuntura Mensal - Açaí (fruto). Disponível em: $<$ http://www.conab.gov.br/OlalaCMS/uploads/arquivos/14 $08 \quad 05 \quad 1107 \quad 18$ acai jul ho 2014.pdf> Acesso em: 16 abr. 2015.

COSTA, L. F. S.; CUNHA, A. H. N.; FERREIRA, E. M.; BRASIL, E. P. F.; FERREIRA, E. P. B. Aplicação de boro em feijoeiro e aspectos microbiológicos do solo. Revista Mirante, Anápolis (GO), v. 7, n. 2, dez. 2014.

CUNHA, J. F.; FRANCISCO, E. A. B; CASARIN, V.; PROCHNOW, L.I. Balanço de nutrientes na agricultura brasileira - 2009 a 2012. Informações agronômicas. n. 145, 2014,28 p.

EMPRESA BRASILEIRA DE PESQUISA AGROPECUÁRIA (Embrapa). Centro Nacional de Pesquisa de Solos. Sistema brasileiro de classificação de solos. 2. ed. Rio de Janeiro: Embrapa Solos. 2006. 
EUBA NETO, M.; FRAGA, V. S.; PEREIRA, W. E.; DIAS, B. O.; SOUTO, J. S. Níveis críticos de boro para a cultura do girassol em solos com texturas contrastantes. Revista Caatinga, Mossoró, v. 27, n. 1, p. 100 - 108, jan/mar. 2014.

FIEAM - FEDERAÇÃO DAS INDUSTRIAS DO ESTADO DO AMAZONAS. Informações gerais sobre o açaí. 2013.

FOY, C. D. Effect of aluminum on plant growth. In: CARSON, F.W., ED. The plant root and its environment. Charlottesville, University Press of Virginia, p. 601-642. 1974.

GONÇALVES, G. K.; MEURER, E. J. Alterações nas concentrações de fósforo em solos cultivados com arroz irrigado no Rio Grande do Sul. Revista Brasileira de Ciência do Solo, Porto Alegre, MG, v. 34, p. 465-471. 2010.

INSTITUTO BRASILEIRO DE GEOGRAFIA E ESTATÍSTICA (IBGE). 2013. Produção da extração vegetal e da silvicultura. Rio de Janeiro, v. 28, p. 1-69. Disponível em: <http://www.ibge.gov.br/home/estatistica/economia/pevs/2013/ default pdf.shtm>. Acesso em: 08 abr. 2014.

KANG, J.; XIE, C.; LI, Z.; NAGARAJAN, S.; SCHAUSS, A. G.; WU, T.; WU, X. Flavonoids from açaí (Euterpe oleracea Mart.) pulp and their antioxidante and antiinflammatory activities. Food Chemistry, Barking, v. 120, p.152-157. 2011.

MALAVOLTA, E. Manual de nutrição mineral de plantas. São Paulo: Agronômica Ceres, 638p. 2006.

MARSCHNER H. Mineral nutrition of higher plants. 3 ed. San Diego: Academic Press, 2012. 651p.

MIWA, K.; FUJIWARA, T. Boron transport in plants: co-ordinated regulation of transporters. Annals of Botany, v. 105, p.1103-1108. 2010.

NOMURA, E. S.; TEIXEIRA, L. A. J.; BOARETTO, R. M.; GARCIA, V. A.; FUZITANI, E. J.; JUNIOR, E. R. D.; SAES, L. A.; JUNIOR, D. M. Aplicação de boro em bananeira. Revista Brasileira de Fruticultura, v. 33, n. 2, p.608-617. 2011.

OLIVEIRA, M. S. P.; FARIAS NETO, J. T.; PENA, R. S. Açaí: técnicas de cultivo e processamento. Fortaleza: Instituto Frutal, p.104. 2007.

REIS, C. J.; SORATTO, R. P.; BISCARO, G. A.; KULCZYNSKI, S. M.; FERNANDES, D. S. Doses e modos de aplicação de boro na produção e qualidade fisiológica de sementes de feijão em solo de cerrado. Agronômica Ceres. Viçosa, v. 55, n.4, p. 258-264, Jul./Ago. 2008.

RUFINO, M. S. M. PÉREZ-JIMÉNEZ, J.; ARRANZ, S.; ALVES, R. E.; BRITO, E. S.; OLIVEIRA, M. S. P.; SAURA-CALIXTO, F. Açaí (Euterpe oleraceae) "BRS Pará": A tropical fruit source of antioxidante dietary fiber and high antioxidant capacity oil. Food Research International, Barking, v. 44, n. 7, p. 2100-2106. 2011. 
SANTANA, A. C.; CARVALHO, D. F.; MENDES, F. A. T. Análise sistêmica da fruticultura paraense: organização, mercado e competitividade empresarial. Belém: Banco da Amazônia, 255 p. 2008.

SILVA, I. F.; BARBOSA, A. M.; TIRITAN, C. S.; CATUCHI, T. A.. Adubação boratada na cultura do arroz em solos de cerrado de baixa fertilidade. Colloquium Agrariae, v. 10, n. Especial, p. 01-08. 2014a. DOI: 10.5747/ca.

SILVA, I. P.; RODAS, C. L.; CARVALHO, J. G. Doses de boro no desenvolvimento do mamoeiro em solução nutritiva. Revista Agrarian. Dourados, v. 7, n. 23, p. 171175. 2014b.

SILVA Jr., M. L.; SOUZA Jr., J. C.; BRAGA, A. C. M.; OHASHI, O. S.; Melo, V. S.; Silva, G. R.; PEDROSO, A. J. S.; VIÉGAS, I. J. M.; SALDANHA, E. C. M. Crescimento de mogno-brasileiro e resistência a Hypsipyla grandella em função do cálcio e do boro. Revista Árvore, Viçosa-MG, v. 38, n. 6, p.1085-1094. 2014.

SOUZA, C. A. S.; TUCCI, C. A. F.; SILVA, J. F; RIBEIRO, W. O. Exigências nutricionais e crescimento de plantas de mogno (Swietenia macrophylla King). Acta Amazonica, v. 40, n. 3, p. 515-522. 2010.

WASTOWSKI, A. D.; ROSA, G. M.; CHERUBIN, M. R.; RIGON, J. P. G. Caracterização dos níveis de elementos químicos em solo, submetido a diferentes sistemas de uso e manejo, utilizando espectrometria de fluorescência de raios-x por energia dispersiva (edxrf). Química Nova, v. 33, n. 7, p. 1449-1452. 2010.

ZHOU, Z.; LIANG, K.; XU, D.; ZHANG, Y.; HUANG, G.; MA, HUAMING. 2012. Effects of calcium, boron and nitrogen fertilization on the growth of teak (Tectona grandis) seedlings and chemical property of acidic soil substrate. New Forrest, v. 43, n. 2, p. 231-243. 2010. 